\title{
LEITURA COMPARTILHADA: UMA PRÁTICA DE LETRAMENTO LITERÁRI0'
}

\section{READING TOGETHER: A PRACTICE OF LITERARY LITERACY}

\section{Rildo Cosson ${ }^{2}$}

RESUMO: Enquanto paradigma de ensino de literatura, o letramento literário pressupõe que determinados princípios teóricos e metodológicos sejam observadas nas atividades pedagógicas. Nesse estudo, apresentamos a prática Leitura Compartilhada, uma sequência didática de leitura e escrita de textos em torno de obras literárias, que segue os princípios do letramento literário. Para tanto, além de apresentar e fundamentar os passos dessa prática de ensino, vamos dar um exemplo concreto de como ela pode ser desenvolvida em sala de aula a partir de uma oficina realizada com professores do ensino básico.

PALAVRAS-CHAVES: Letramento literário. Leitura literária. Leitura compartilhada. Ensino de literatura. Prática de ensino.

ABSTRACT: As a paradigm for literature teaching, the literary literacy has theoretical and methodological principles that must be observed in the learning activities. In this paper, we will introduce the Reading Together practice, a pedagogical sequence of reading and writing texts around literary works, which follows the literary literacy principles. In this way, we will provide conceptual details about the teaching practice and an example how it can be managed in the classroom. This example comes from workshops that we developed with schoolteachers.

KEYWORDS: Literary literacy. Literary reading. Reading together. Literature teaching. Teaching practice.

\section{0 ensino de literatura como leitura literária}

Na abertura do ensaio "Como ensinar Literatura", de 1976, Jacinto do Prado Coelho, renomado crítico literário português, descreve uma aula de literatura como um momento de compartiIhamento festivo em torno de uma obra. Na sábia elaboração do autor, "aulas em que se fale de literatura, em que se comungue no amor da literatura, têm algo de festa ritual, inunda-as a alegria

\footnotetext{
${ }^{1}$ Artigo recebido em 24/03/2020 e aceito para publicação em 25/05/2020.

${ }^{2}$ Doutor em Letras pela UFRGS e Educação pela UFMG; Professor visitante do Programa de PósGraduação em Letras da UFPB; Orcid ID: https://orcid.org/0000-0003-2677-5149; ResearcherID: H-6621-2017; Scopus Author ID: 56351635600; E-mail: rcosson@gmail.com.
} 
de, num impulso coletivo, descobrir, clarificar, ficando cada um enriquecido, dinamizado". Esse enriquecimento mútuo, esclarece Prado Coelho, acontece porque:

Ler coletivamente (em diálogo com a obra literária, em diálogo do leitor com outros leitores) é, com efeito, além de prazer estético, um modo apaixonante de conhecimento, o ensejo inestimável de participar ativamente, ampliando a criação pelo comentário, pondo-se cada um à prova, jogando-se, inteiro, na aventura em que a palavra estética nos envolve, e ao mundo (PRADO COELHO, 1976, p. 45).

Desenvolvendo sua argumentação em vários tópicos, Prado Coelho critica a insistência no ensino historiográfico, a análise meramente temática das obras e o fragmentarismo dos textos, entre outras dificuldades do ensino da literatura em sua época (!). A solução dada pelo autor é, essencialmente, ensinar a ler criticamente as obras literárias, conforme sintetiza nas palavras abaixo:

No meu entender, tanto no liceu como nas Faculdades de Letras às disciplinas literárias compete uma função mais formativa que informativa, pensando-se, claro, numa formação integral do espírito; devem, acima de tudo, ensinar a ler e despertar nos alunos a forma da leitura. Ler com inteligência e finura, ler criticamente - é uma arte difícil (PRADO COELHO, 1976, p. 58).

Mais adiante no ensaio, para não deixar dúvidas quanto a sua posição, o autor insiste em dizer que: "Ensinar a ler [a ler integralmente e em profundidade] - eis, repito, em qualquer grau de ensino, o objetivo fundamental das disciplinas literárias" (PRADO COELHO, 1976, p. 63).

A despeito de terem sido escritas há quase meio século, essas palavras poderiam traduzir, embora não sem acréscimos e alguns reparos provenientes de novas afiliações teóricas, o que vários estudiosos e professores de literatura apontam como o caminho a ser seguido para o ensino de literatura na contemporaneidade. É o que faz, por exemplo, Regina Zilberman (2008), em um dos vários diagnósticos que fez sobre o lugar e importância da literatura na formação do aluno. A autora destaca que foram muitas as transfor-

Interdisciplinar, Săo Cristóvăo, UFS, v. 33, jan-jun, p. 13-29, 2020 D0I: https://doi.org/10.47250/intrell.v33il.14174 
mações que ocorreram nesses últimos tempos envolvendo tanto manifestações culturais diversas, quanto o modo de compreendê-las, aí incluindo concepções sobre educação, leitura e literatura, mas que a escola permanece estagnada, incapaz de absorver essas mudanças. Para Zilberman, a leitura literária, o letramento literário, a aprendizagem de um modo específico de ler o texto literário poderia ser um dos caminhos para reafirmar a valor e necessidade da formação escolar que tem dificuldade em se manter frente as facilidades da comunicação de massa e da cultura digital. Nas palavras da autora, a "sobrevivência [da escola] enquanto instituição, portanto, depende de um posicionamento na vanguarda dos fatos históricos", para isso precisa antes de mais nada "se solidarizar a seus usuários, servir-lhes de veículo para manifestação pessoal e colaborar para sua autoafirmação". É aqui que entra o papel fundamental da leitura literária como ensino da literatura, pois "o exercício da leitura do texto literário em sala de aula pode preencher esses objetivos, conferindo à literatura outro sentido educativo, auxiliando o estudante a ter mais segurança relativamente às suas próprias experiências" (ZILBERMAN, 2008, p 18).

Também Neide de Resende, constatando que a história da literatura ainda é o conteúdo dominante do ensino da literatura no nível médio, defende que a leitura literária deveria ocupar o centro do ensino de literatura, fazendo com que os textos literários sejam efetivamente "apropriados pela escola como conteúdo de ensino" (RESENDE, 2013, p. 106). Na concepção da autora, tal mudança poderia levar a uma nova relação pedagógica, agora centrada no aluno e não mais no professor, transformando a prática escolar dominante ainda presa a modelos do passado e dos quais tem dificuldade de se desvencilhar. Também aproximaria o ensino da literatura da prática social de ler obras literárias. Dessa forma, diz Resende em outro texto, ensinar literatura na escola "trata-se menos de ensinar um conteúdo, mas de ensinar um modo de ler", ou seja, a leitura literária que se faz pela "implicação do sujeito leitor na obra, dando impulso a seu investimento imaginário, convidando-o a exprimir sua percepção da obra de modo a promover uma efetiva participação no ato de leitura" (RESENDE, 2009, s. p., destaques da autora).

Para tornar esse aparente consenso em realidade da sala de aula não faltam propostas. Estudos acadêmicos variados que 
vão de trabalhos de iniciação à pesquisa científica a teses de doutorado, passando por trabalhos de conclusão de curso e dissertações de mestrado, com destaque para os projetos de intervenção de alunos do Mestrado Profissional em Letras (Profletras), além de publicações diversas em revistas e anais de eventos, comprovam facilmente a preocupação em fazer da leitura de textos literário o centro do ensino de literatura. Apenas para registro da quantidade desses estudos, em consultas feitas em 15 de abril de 2020, uma simples busca no Google Acadêmico com o termo "leitura literária", excluída citações, trouxe mais de 12.000 resultados e quando combinada com "ensino" cerca de 10.000 resultados. Os números são igualmente altos quando o termo "leitura literária" é combinado com "escola" (+10.000), "práticas" (+9.500) e "sala de aula" (+9.000). Também o termo "letramento literário" traz mais de 5.000 resultados. O catálogo de teses e dissertações da Capes, por sua vez, traz quase 1.000 resultados para "leitura literária" e "letramento literário" em separado.

Uma parte dessas propostas tem buscado e encontrado suporte metodológico nos pressupostos do letramento literário ${ }^{3}$, ainda que nem sempre adotando seus princípios teóricos ou justapondo abordagens com bases conceituais bem distintas, conforme chamamos a atenção em relação ao Profletras (COSSON, 2019). Não obstante, de uma forma ou de outra, em adoções plenas, reduzidas ou adaptadas, esses estudos acadêmicos são em geral bastante felizes ao explorar as possibilidades dadas pelo paradigma do letramento literário de exercitar a leitura literária em sala de aula. Neste artigo vamos nos alinhar com os autores desses estudos, quase todos professores de literatura como nós, e propor uma prática de letramento literário que denominamos de Leitura Compartilhada.

Essa prática tem origem em vários minicursos e oficinas que ministramos em eventos como uma forma pragmática de demonstrar o funcionamento de uma aula de literatura dentro dos pressupostos do letramento literário. Procurando ser fiel a essa origem, a apresentação da Leitura Compartilhada que faremos a

\footnotetext{
${ }^{3}$ Em estudo sobre o Profletras, Adriana Precioso e Rosana Silva afirmam que "o Profletras impulsionou os estudos na área do letramento literário, na medida em que tem propiciado a discussão teórica e metodológica do ensino da literatura e tem desenvolvido práticas interventivas no contexto escolar" (PRECIOSO e SILVA, 2016, p. 279).
} 
seguir se configura metodologicamente como um misto de reflexão teórica e relato de experiência e tem por objetivo introduzir uma sequência didática alternativa de letramento literário na escola. Para tanto, o artigo está dividido em três tópicos. No primeiro deles, faremos um breve percurso pelos pontos conceituais sobre ensino de literatura que são relevantes para a elaboração da proposta. No segundo, descreveremos a proposta em detalhes. No terceiro, exemplificaremos a partir de uma experiência realizada com professores de ensino básico o funcionamento da prática da Leitura Compartilhada.

\section{0 letramento literário na escola}

Quando se trabalha com ensino de literatura, sobretudo no ensino fundamental, há uma certa confusão entre a formação do leitor e a formação do leitor literário. Embora não se possa falar em um sem o outro, a superposição que se faz entre eles muitas vezes termina, por questões pragmáticas do ensino da escrita e suas dificuldades, gerando o apagamento da especificidade do leitor literário. Aliás, para uma parte dos professores de língua materna, a literatura nem mesmo é o instrumento mais adequando para a formação do leitor, dada a preferência acentuada por textos e atividades que envolvem jornais e outros impressos ou textos digitais. Quando muito, a literatura é matéria de fruição, o que significa que as obras literárias devem ser lidas em momentos de lazer ou no máximo como suplemento das 'verdadeiras' atividades de formação do leitor que se faz sob supervisão do professor em sala de aula.

No entanto, ler literariamente não é decorrência natural da aprendizagem da escrita. Antes precisa ser matéria de ensino na escola tal como qualquer outra competência cultural considerada relevante para a formação integral do ser humano. Para isso, é preciso romper com as limitações que a escolarização inadequada da literatura costuma impor à formação do leitor literário. Na análise de Graça Paulino, "os modos escolares de ler literatura distanciam-se de comportamentos próprios da leitura literária, assumindo objetivos práticos, que passam da morfologia à ortografia sem qualquer mal-estar". Tanto é assim que "se for perguntado a

Interdisciplinar, Săo Cristóvăo, UFS, v. 33, jan-jun, p. 13-29, 2020 D0I: https://doi.org/10.47250/intrell.v33i1.14174 
um professor de português no Brasil que tipo de leitor quer formar" a reposta mais provável "instituirá idealizações distantes das práticas culturais ou destacará habilidades típicas do letramento funcional, ligadas à leitura de textos básicos para a vida diária do cidadão" (PAULINO, 2004, p. 56). Em consequência, vem a dificuldade de reconhecer que o leitor literário é um leitor distinto do leitor em geral, que precisa atender a demandas específicas no tratamento dos textos. Como bem diz a autora:

\footnotetext{
Esse leitor tem de saber usar estratégias de leitura adequadas aos textos literários, aceitando o pacto ficcional proposto, com reconhecimento de marcas linguísticas de subjetividade, intertextualidade, interdiscursividade, recuperando a criação de linguagem realizada, em aspectos fonológicos, sintáticos, semânticos e situando adequadamente o texto em seu momento histórico de produção (PAULINO, 2004, p. 56).
}

Para formar o leitor literário, portanto, não basta o ensino da escrita. Nem o simples acesso aos textos em atividades de fruição. Nem visitas programadas à biblioteca da escola. Nem a animação da leitura, por mais prazerosas que possam ser as atividades que motivam e incentivam a leitura. Tudo isso conta, é verdade, mas não é suficiente. É preciso ir além e promover uma aprendizagem sistematizada e sistemática da leitura literária pela qual se potencializa e diversifica o letramento literário. Em outras palavras, na escola, o letramento literário tem por objetivo desenvolver a competência literária, usando, como meio, experiências literárias diversas e diversificadas, e buscando, como resultado, a ampliação e aprimoramento do repertório literário do aluno (COSSON, 2014).

Traduzindo esses princípios para a sala de aula, o professor deve ter claro que a aprendizagem literária se faz em círculos concêntricos que começam com a leitura individual do aluno em diálogo com a obra e avançam progressivamente para a leitura em diálogo com os colegas da turma, com os colegas e o professor, com a turma, o professor e outros leitores externos que são a crítica, a história, outros textos que também dialogaram como aquele, conforme se ver na ilustração abaixo. 
Figura 1 - Círculos de aprendizagem literária

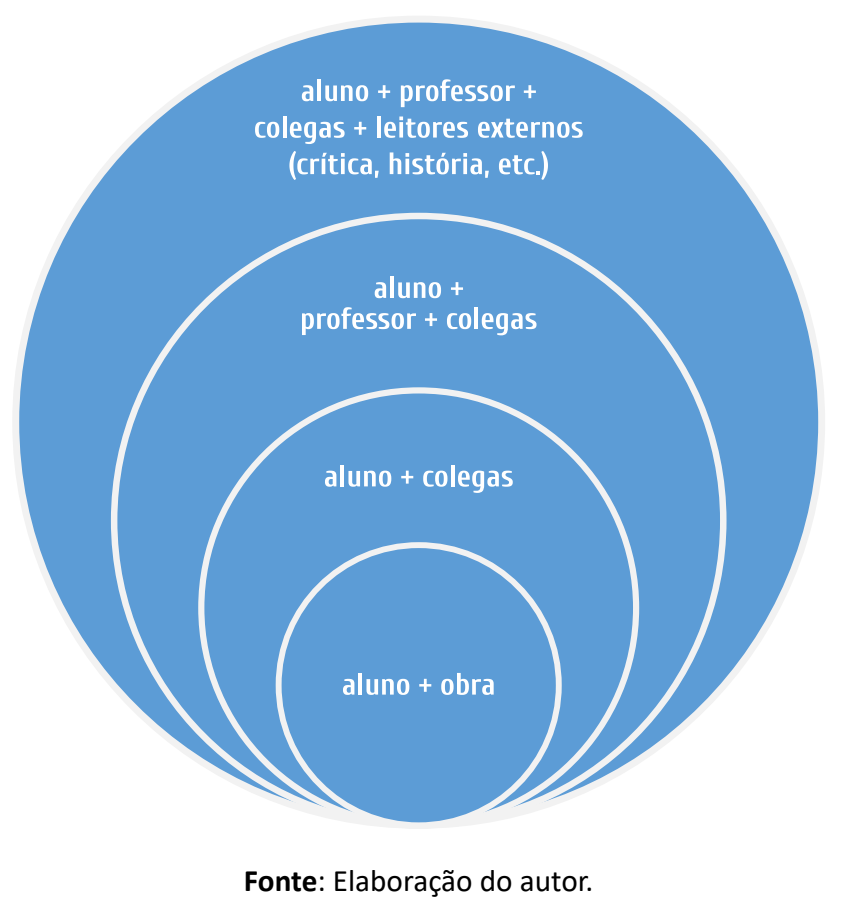

Dessa forma, é papel do professor de literatura promover o compartilhamento da leitura literária, fazendo da leitura privada uma leitura pública. Nesse compartilhamento que fundamenta o letramento literário, deve seguir pressupostos similares àqueles que orientam as abordagens de ensino baseadas em discussão aplicadas ao ensino da literatura (APPLEBEE et al., 2003; GABRIELSEN et al., 2019). Em primeiro lugar, deve compreender que o compartilhamento precisa envolver todos os alunos e que todos os alunos contribuem individual e coletivamente para a compreensão e interpretação do texto literário. Depois, que compartilhar a leitura literária significa colocar em discussão emoções, impressões, pressuposições e questionamentos quanto mais autênticos mais valiosos no diálogo com o texto literário. Também que o objetivo da leitura literária é desenvolver a interpretação e não impor ou confirmar uma interpretação que do professor ou de qualquer outro leitor considerado autorizado. Por fim, que não há necessidade de se chegar a uma leitura única e consensual para toda a turma, ao contrário as diferentes perspectivas servem para ampliar e enriquecer a leitura literária daquele texto. 


\section{A prática Leitura Compartilhada}

No livro Letramento literário: teoria e prática (COSSON, 2006), indicamos que a organização de uma sequência didática de letramento literário deve adotar determinados princípios técnicos para ser bem-sucedida. Dessa forma, precisa levar em conta que o aluno aprende a fazer fazendo, isto é, que ele constrói pela prática o seu conhecimento (técnica da oficina). Também que convém dividir com o aluno e, em alguns casos, transferir para ele, a edificação do conhecimento, cabendo ao professor atuar como um mediador, sustentando as atividades a serem desenvolvidas autonomamente pelo aluno (técnica do andaime). Finalmente, que é preciso manter um registro das diversas atividades realizadas em um curso, possibilitando a visualização do crescimento alcançado pela comparação dos resultados iniciais com os últimos (técnica do portfólio).

Esses princípios técnicos, assim como as questões teóricas elencadas anteriormente, estão na base da proposta de Leitura Compartilhada. Ela começa com a seleção de dois, três ou quatro textos que possam ser relacionados entre si por questões temáticas, formais ou intertextuais. $O$ ideal é que esses textos sejam diversos entre si em termos de complexidade para que a leitura seja enriquecida pela relação a ser estabelecida entre eles. Selecionados os textos, passa-se para o ordenamento da leitura inicial que deve ser feita do mais complexo para o mais simples a fim de que a compreensão imediata do texto mais simples não determine e obscureça a leitura do mais complexo. Durante essa leitura inicial, que deve ser feita, preferencialmente, extraclasse, o aluno deve elaborar uma memória da leitura para registro e compartilhamento posterior.

Após essa fase preliminar ou preparatória, vem a execução propriamente dita. A sala de aula deve ser dividida em dois espaços: um para grupos composto por no máximo quatro alunos e outro para uma plenária. Estando todos de posse dos textos, o professor inicia a prática pela leitura oral integral ou parcial do texto mais simples, invertendo a ordem da leitura inicial, pois agora a ênfase é na interpretação e não mais apenas na compreensão. Após a leitura oral do texto, os alunos são divididos em grupos, para compartilhamento das memórias e com uma pergunta específica a ser respondida por escrito para aquele texto, com a escolha de um relator. 
Durante o tempo de compartilhamento e resolução da pergunta, o professor passa por todos os grupos verificando as respostas e ajudando a aprofundar a interpretação. Tendo todos os grupos respondido a pergunta motivadora, os alunos voltam para a plenária e os relatores são chamados a apresentar a resposta do grupo que é aberta para a discussão da turma. Como as perguntas são específicas a cada grupo, as respostas tendem a apresentar diferentes interpretações do texto. Ao final, o professor pode fazer uma síntese oral das interpretações feitas pelos alunos, podendo também chamar a atenção para detalhes que passaram despercebidos ou acrescentando aspectos de sua própria interpretação, devendo os alunos revisarem individualmente o texto escrito no grupo.

As próximas duas ou três rodadas de leitura seguem os mesmos procedimentos, sendo que as atividades podem ser feitas em bloco único, em aulas pareadas ou com uma aula para cada uma delas. Na composição dos grupos, porém, um novo relator deve ser designado e o relator anterior deve mudar para um outro grupo. Essa rotatividade é necessária para que haja não só uma maior interação entre os alunos, que vão compartilhando suas memórias em novos grupos, como também para que um número maior de alunos tenha a possibilidade de falar para a turma em nome do grupo.

Ao final, para encerrar a atividade, a turma é convidada pelo professor para reler e discutir comparativamente os textos, destacando pontos de intersecção construídos durante a leitura individual e interpretação coletiva feita durante as aulas que devem ser subsequentes e o mais próximas possíveis ou até mesmo em um único dia. Posteriormente, os textos produzidos no calor da hora podem ser a base para um registro pessoal de cada aluno sobre os textos, realizado em sala de aula ou extraclasse, na forma de um relatório, ensaio, entrada de diário ou outra maneira mais criativa, a ser compartilhado coletivamente em um mural ou coletânea.

\section{A experiência de professores de ensino básico}

Realizamos a prática da Leitura Compartilhada com uma turma de professores do ensino básico. A experiência aconteceu como parte de um evento maior, um Seminário com palestras, mesas-redondas e comunicações, na forma de uma oficina de 
quatro horas presenciais e duas horas não presenciais. A turma foi limitada a 16 vagas por força da concentração das leituras em um único dia e o desejo de uma maior interação entre os participantes. A inscrição na oficina tinha como única exigência que o candidato fosse professor em atuação no ensino básico e disponibilidade para as leituras prévias.

Duas semanas antes da realização do evento, a turma já havia sido constituída. Os inscritos eram todos professores formados em Letras, um deles com mestrado em Linguística e seis com especialização lato sensu na área de Educação. A atuação era predominantemente no ensino médio, que ficou com cerca de $65 \%$ das vagas. A turma era constituída majoritariamente de mulheres: dos 16 inscritos, 14 eram do sexo feminino, o que reflete uma distribuição comum e pouco problematizada nos cursos de Letras no país (OLIVEIRA, 2016). Apesar de a maioria dos participantes estar na faixa etária dos 30 a 35 anos (65\%), havia também professores mais jovens, na faixa de 22 a 30 anos (20\%) e mais maduros, na faixa de 40 a 48 anos (15\%). A experiência de sala de aula era variada, com peso maior para professores mais experientes: $35 \%$ dos inscritos possuía mais de 10 anos de magistério, 30\% mais de cinco anos, $20 \%$ entre dois e cinco anos e $15 \%$ menos de dois anos. Dos professores com atuação no ensino médio, nenhum deles era ou havia sido exclusivamente professor de literatura, disciplina que apenas três havia ministrado anteriormente, ainda que todos afirmassem trabalhar com textos literários em sala de aula e a principal motivação para participar da oficina ser justamente a dificuldade que enfrentavam para ensinar literatura. Essa motivação, aliás, era de todos os inscritos, independentemente do nível de ensino de atuação. Tal informação já era pressuposta tendo em vista que os cursos de Letras apenas muito recentemente passaram a se preocupar com o ensino de literatura e, mesmo assim, ainda de forma pouco sistemática (COSSON e FIDÉLIS, 2016; DALLA-BONA e MARTINS, 2017).

Uma vez constituída a turma, passamos para a fase da preparação da prática. Para a seleção dos textos tomamos como princípio a relação temática por ser de apreensão imediata e como tema a relação amorosa e suas dificuldades por sua universalidade cultural. A essa ideia inicial de facilitar a leitura dos textos abordando um tema bastante conhecido e com uma relação facilmente 
estabelecida entre eles, acrescentamos como contraponto o princípio da diversidade formal, usando textos em diversos suportes e gêneros. Também adotamos textos de complexidade variada e com abordagem voltada para a faixa etária dos participantes. Dentro do universo ainda bastante amplo de possibilidade de seleção dado por esses princípios, tivemos, ainda, a preocupação que os textos não fossem facilmente transferidos juntamente com a prática para as salas de aula do ensino básico, ou seja, a ideia era que aquela prática deveria se constituir não apenas como a aprendizagem de uma estratégia didática, mas também que se efetivasse como uma experiência de leitura literária para os participantes.

Reunidos todos esses critérios, selecionamos, dentro de nosso repertório, três textos. O primeiro deles foi o conto "A muIher de Ouro", de Myriam Campello (1998), escritora brasileira contemporânea. Trata-se de uma narrativa autodiegética na qual a protagonista relata, para si mesmo e para uma audiência aqui e ali retoricamente nomeada, o fim de um casamento e a libertação do mito do amor romântico, o encontro inesperado e intenso com uma mulher e a resistência ou dificuldade de viver outro compromisso amoroso. O conto é composto por uma cerrada rede de citações literárias que vão do erudito ao popular, passando pela cultura de entretenimento, incluído também referências históricas e religiosas. O resultado é a sensação de estar lendo um texto que funciona como um caleidoscópio em movimento contínuo. A enxurrada de citações que entretece a história é a forma como a autora procura dar conta do impacto físico e emocional vivido pela personagem a partir do encontro com a 'mulher de ouro'.

Por essas características, não é um texto simples e demanda uma certa bagagem cultural para acompanhar os intertextos que a todo momento despontam na narrativa e que, como hiperlinks de um texto digital, podem distrair e dispersar a atenção do leitor. Essa dificuldade foi relatada por todos os participantes e demandou um rápido levantamento e explicitação coletiva dos diversos intertextos antes da leitura em grupo, uma etapa de compreensão que não estava prevista inicialmente na prática. Também por abordar uma relação homossexual de forma aberta e sensual, ainda que poeticamente descrita, o conto pode suscitar algum estranhamento entre leitores, como de fato aconteceu com as professoras na faixa etária dos 40 a 48 anos. 
O segundo texto foi um vídeo no youtube "Só de mim", realizado por Ana Luisa Bairos (2012a) e equipe, com direitos autorais reservados para Diffuse Studios. Além do texto escrito por Ana Luisa Bairos com Joana Pacheco e revisto por Margarida Vaqueiro Lopes, o vídeo conta com o ator Diogo Lopes e música de Alexandre Pereira. A ideia original, segundo relata Bairos (2012b) em seu blog, vem de um outro vídeo em inglês "The Emotive" escrito por Chris King Wong e produzido por Kevin Guiang. Uma comparação entre os dois vídeos, entretanto, mostra que Bairos fez mais do que uma versão em português. Embora textualmente muitos próximos, ela recriou a ideia original em um vídeo esteticamente independente e de forte impacto emocional. O vídeo é uma espécie de diálogo, que funciona como um monólogo porque o outro só está presente como interpelação, entre o ex-parceiro amoroso e o novo parceiro de uma mulher. A fala assume o tom de um longo conselho do ex-parceiro para que o novo parceiro não cometa os mesmos erros no relacionamento e a termine perdendo como aconteceu com ele. Essa fala de dor e arrependimento amoroso, que revela hábitos da mulher e momentos de cumplicidade de um casal, é pontuada por uma música plangente e imagens da grande Lisboa que sugerem a solidão interior do ex-parceiro.

É difícil assistir ao vídeo e não se emocionar. Praticamente todos os participantes relataram que ao final do vídeo estavam em lágrimas. A despeito desse impacto, ele apresenta certa dificuldade linguística para os brasileiros, uma vez que o registro é do português de Portugal. Por isso, vários participantes reclamaram da dificuldade entender algumas palavras, mesmo tendo assistido repetidas vezes. Para contornar essa dificuldade, encaminhamos também o texto por escrito após o primeiro contato com o vídeo.

$O$ terceiro e último texto foram três figurinhas da série Amar é... de Kim Grove, escritora neozelandesa, de grande sucesso nas décadas de 1970 e 80 . Escritas inicialmente para o namorado italiano que depois se tornaria marido, Roberto Casali, as figurinhas mostram um casal e uma frase que começa sempre com "Amar é" e continua com uma afirmativa sobre relacionamento amoroso (CF. LIMA Jr., 2014). As figurinhas que selecionamos continham as seguintes foram "Amar é... compartilhar bons momentos", "Amar é... pensar nele o tempo todo" e "Amar é... escutar sempre o que ela tem a dizer" retirados de uma coletânea do blog Figurinhas Amar é... (2011). 
Os dois primeiros textos foram enviados com intervalos de quatro dias entre eles uma semana antes do evento. A orientação era que os participantes, agora na condição de alunos, deveriam ler o texto de uma única vez, sem interrupções. Durante a leitura, deveriam fazer anotações sobre o texto, como em um diário íntimo, sem se preocupar com a forma ou conteúdo, pois todo e qualquer registro, fosse palavra ou frase, era importante. Também solicitamos que não compartilhassem suas impressões de leitura com colegas, pois o compartilhamento seria feito em sala de aula.

O terceiro texto não foi encaminhado para leitura prévia porque a intenção era que fosse usado para introduzir e motivar o trabalho de sala de aula. Dessa maneira, quando nos reunimos com a turma, a primeira atividade foi justamente a apresentação das figurinhas. Ao contrário do imaginado, poucos alunos conheciam ou lembravam das figurinhas, o que demandou uma apresentação um tanto mais longa sobre sua origem e uso entre adolescentes em seu período de maior sucesso. Dadas as explicações, os alunos foram divididos em grupos com a tarefa de cada grupo produzir duas frases de "Amar é...". O objetivo era fazer com que interagissem em uma atividade rápida, simples, quase pueril, em torno da temática amorosa. $O$ resultado desse aquecimento foi uma adesão entusiasmada, com os quatro grupos produzindo não apenas duas, mas quatro frases, uma vez que cada membro reivindicava ter a sua própria frase. Algumas delas, acompanhavam o espírito romântico figurinha atualizando para o momento atual, como "Amar é... trocar o facebook por um momento registrado para sempre somente na memória" (A1) e "Amar é... esperar o outro para assistir ao último episódio da série favorita" (A2). Outras, mais críticas, assumiam um tom realista em relação ao relacionamento amoroso, a exemplo de "Amar é... permitir ser você mesma" (A4) e "Amar é... cozinhar para sua amada mesmo ela reclamando da comida" (A5). Algumas, ainda, adaptavam a frase para questões mais pessoais, como "Amar é... esperar cheia de aflição a chegado do melhor de mim, a bebê"(A6). Ao final, mesmo tomando um tempo maior do que o planejado, a elaboração das frases cumpriu com eficiência o duplo objetivo de preparar

${ }^{4}$ Cumprindo a promessa de anonimato dada aos participantes, vamos nomear a autoria dos textos produzidos com a letra A seguida de um número que segue a ordem de citação neste estudo. 
tematicamente os alunos para a leitura dos textos e para a sistemática do compartilhamento entre grupo e plenária.

Seguindo a ordem invertida da leitura dos textos, a atividade seguinte foi a leitura do vídeo "Só de mim". Primeiro, a turma assistiu coletivamente o vídeo em silêncio. Depois, fizemos uma apresentação muito breve de sua autoria, origem e contexto de produção. Aproveitando que o vídeo começa com uma interpelação, uma tarefa dada para um dos grupos foi que assumisse o diálogo e respondesse como se fosse o interlocutor; outro grupo ficou responsável por dar voz à mulher referida; um outro recebeu a tarefa de analisar as razões da personagem para ter aquele discurso e o último grupo de identificar o que seria um relacionamento amoroso ideal conforme exposto no vídeo. O objetivo era que os alunos, além de compartilharem suas impressões, interagissem com o texto adotando diferentes perspectivas de análise.

$\mathrm{Na}$ leitura de "A mulher de Ouro", devido ao tempo dispendido no levantamento dos intertextos feito coletivamente logo após a rápida apresentação da autora e da obra, as tarefas que seriam distintas por grupo foram reduzidas a uma só: dar continuidade à narrativa tendo passado uma década após o momento final descrito no conto. A intenção era que, ao assumir a voz da protagonista, os grupos fossem além do processo de identificação e acrescentassem olhar mais analítico sobre escolha que ela faz em se recusar a viver uma relação amorosa ditada pelas convenções românticas, ainda que tomada por uma paixão intensa.

Não é possível reproduzir aqui, por questão de extensão, os vários textos que foram produzidos pelos alunos nas duas leituras. As repostas dadas ao vídeo foram, obviamente, muito mais emocionais e emocionadas do que ao conto. Mesmo assim, nas discussões que seguiram à apresentação de cada grupo, foi possível ir além da simples adesão ao sentimento de perda que é encenado no texto. Alguns alunos, por exemplo, questionaram a generosidade do ex-parceiro e perguntaram se não estava ali uma estratégia discursiva de reconquista ou até mesmo de ameaça ao novo relacionamento. Outros concluíram que não há perda sem crescimento e que a idealização do passado em nada ajuda a ir em frente quando as relações amorosas chegam ao fim.

No caso do conto de Myriam Campello, a continuidade dada à narrativa oscilou entre manter a decisão de romper com o 
padrão romântico da relação amorosa pagando o preço da solidão e o arrependimento amargo por não ter aceitado o relacionamento proposto, não faltando um final feliz nas duas situações, quer sob a forma de superação ou de conformismo. Nos textos produzidos pelos alunos, todos perpassados por uma certa melancolia, e na discussão que se seguiu à apresentação deles, foi flagrante o apagamento da questão do relacionamento homossexual como um elemento relevante da trama assim como certa dificuldade em reconhecer, como padrões culturais longamente alimentados, as convenções que ainda hoje cercam e determinam o relacionamento amoroso. Talvez, por isso, tenha se destacado um texto muito curto que, diferentemente dos demais, parece interpretar o conto com mais pertinência:

Ao passar por aquela praça, dez anos depois, não havia mais as cinzas do meu desespero. Naquele local, antes cinza, agora havia uma roseira com uma única flor em meio a inúmeros espinhos. Sorri. Gargalhei. Gargalhei muito. Assustei todos ao redor. Não, não quero aquela rosa. Nem os espinhos. Quero o néctar. (A7).

\section{Para refletir}

A transposição da prática da Leitura Compartilhada para o funcionamento regular de uma sala de aula do ensino básico pode enfrentar dificuldades e resistências para alunos e professores que concebem a aula de literatura segundo o roteiro de preleção e exercício dos livros didáticos. Também pode ser um desafio para aqueles que acreditam que a leitura literária na escola deve ser um simulacro da leitura silenciosa e solitária dos leitores maduros e abastados em suas horas de lazer. Mas para aqueles que sabem que ensinar a leitura literária na escola é um dever da escola, um dos caminhos a ser trilhado é a seleção de textos relevantes para a atividade e o aluno, com a interpretação do texto realizada a partir dos conhecimentos e experiência do leitor e compartilhada com outros leitores, como se propõe aqui com a prática da Leitura Compartilhada. Afinal, como nos lembrava bem Prado Coelho há quase cinquenta anos atrás: 
Não há, suponho, disciplina mais formativa que a do 'ensino' da literatura (...). Saber idiomático, experiência prática e vital, sensibilidade, gosto, capacidade de ver, fantasia, espírito crítico - a tudo isto faz apelo a obra literária, tudo isto o seu estudo mobiliza. O que não significa, é evidente, que a literatura se confunda com pedagogia. A literatura não se fez para ensinar: é a reflexão sobre a literatura que nos ensina (PRADO COELHO, 1976, p. 46).

\section{Referências}

APPLEBEE, A. N. et al. Discussion based approaches to developing understanding: Classroom instruction and student performance in middle and high school English. American Educational Research Journal, n. 40, v. 3, p. 685-730, Autumn 2003. Disponível em: http://links.jstor.org/sici?sici=0002-8312\%28200323\%2940\%3A3\%3C685\%3ADATDUC\%3E2.0.CO\%3B2-1. Acesso em: 10 fev. 2017.

BARIOS, A. L. Só de mim. Direitos autorais Diffuse Studios. Youtube, 2012a. Disponível em: https://www.youtube.com/watch?v=DmkvkbqXY_Q Acesso em: 12 jun. 2013.

BARIOS, A. L. Só de mim: O meu contributo para o dia dos namorados. Blog. Doce para o meu doce, 2012b. Disponivel em: http://www.doceparaomeudoce.com/2012/02/so-de-mim-o-meu-contributo-para-o-dia.html Acesso em: 12 jun. 2013.

CAMPELLO, M. A mulher de ouro. In: CAMPELLO, M. Sons e outros frutos. Rio de Janeiro/São Paulo: Record, 1998.

COSSON, R. Letramento literário: teoria e prática. São Paulo: Contexto, 2006.

COSSON, R. Círculos de leitura e letramento literário. São Paulo: Contexto, 2014.

COSSON, R. Método com teoria: o ProfLetras e o letramento literário. In: MACIEL, R. F. e SANTOS, L. I. S. (Org.). Formação e prática docente em língua portuguesa e literatura. 1ed.Campinas: Pontes, 2019, v. 1, p. 23-40.

COSSON, R. e FIDÉLIS, A. C. E. S. Os (des)caminhos da literatura no ensino médio. In: MARTINI, M. et al. (Orgs.). Literatura na escola: teoria, prática e (in) disciplina. 1ed. Santa Maria, RS: UFSM, PPGL-Editores, 2016.

Interdisciplinar, Săo Cristóvăo, UFS, v. 33, jan-jun, p. 13-29, 2020 D0I: https://doi.org/10.47250/intrell.v33i1.14174 
DALLA-BONA, E. M., e MARTINS, M. R. Desafios na formação do licenciando em Letras como leitor e a sua atuação na educação básica. Revista Desenredo, v. 12, n. 2, p. 353-375, 2017. Disponível em: https://doi.org/10.5335/rdes. v12i2.6744 Acesso em: 05 maio 2018.

FIGURINHAS Amar é. Blog. Disponível em: http://figurinhas-amar-e.blogspot. com/2011/06/figurinhas-amar-e.html Acesso em: 17 fev. 2017.

GABRIELSEN, I. L. et al. The role of literature in the classroom. How and for what purposes do teachers in lower secondary school use literary texts? L1-Educational Studies in Language and Literature, v. 19, p. 1-32, 2019. Disponível em: https://doi.org/ 10.17239/L1ESLL-2019.19.01.13 Acesso em: 02 mar. 2020.

LIMA Jr., J. Amar é... Design Innova. Blog. 18 de outubro de 2014. Disponível em: https://designinnova.blogspot.com/2014/10/amar-e.html Acesso em: 17 fev. 2017.

OLIVEIRA, H. F. Indivíduos do sexo masculino no curso de letras: performances discursivas, gênero e profissão docente. Revista Brasileira de Estudos Pedagógicos, Brasília, v. 97, n. 247, p. 552-569, dez. 2016. Disponível em: http://www.scielo.br/ scielo.php?script=sci_arttext\&pid=S2176-66812016000300552\&lng=en\&nrm=iso. Acesso em: 18 abril 2019.

PAULINO, Graça. Formação de leitores: a questão dos cânones literários. Revista Portuguesa de Educação, v. 17, n. 1, p. 47-62, 2004. Disponível em: https:// www.redalyc.org/pdf/374/37417104.pdf Acesso em: 10 jun. 2010.

PRADO COELHO, J. Como ensinar literatura. In: PRADO COELHO, J. Ao contrário de Penélope. Venda Nova: Bertrand Editora, 1976.

PRECIOSO, A. L. e SILVA, R. R. Avanços e processos do ensino de literatura: práticas interventivas do Profletras. Revista Cerrados, v. 25, n. 42, p. 267-282, 2016. Disponível em: http://periodicos.unb.br/index.php/cerrados/article/view/267282/pdf Acesso em: 15 maio 2018.

RESENDE, N. L. O ideal de formação pela literatura em conflito com as práticas de leituras contemporâneas. In: Literatura, crítica, leitura. Anais do SILEL, v. 1. Uberlândia: EDUFU, 2009. Disponível em: http://www.ileel.ufu.br/anaisdosilel/wpontent/uploads/2014/04/silel2009_gt_tt01_artigo_8.pdf Acesso em: 11 jun. 2018.

RESENDE, N. L. O ensino da literatura e a leitura literária. In: RESENDE, N. L. et al. (Orgs.). Leitura de literatura na escola. São Paulo: Parábola,2013.

ZILBERMAN, R. O papel da literatura na escola. Via atlântica, n 14, p. 11-22, dez. 2008. Disponível em: http://www.revistas.usp.br/viaatlantica/article/ view/50376. Acesso em: 21 set. 2010. 